\title{
Effects of disease modifying therapies on brain and grey matter atrophy in relapsing remitting multiple sclerosis
}

\author{
Alice Favaretto, Andrea Lazzarotto, Monica Margoni, Davide Poggiali and Paolo Gallo* (0)
}

\begin{abstract}
Background: Progressive brain atrophy is a major feature of multiple sclerosis (MS) pathology and is actually considered a major determinant of the progressive accumulation of physical and cognitive disability in MS patients. Although brain atrophy may have different pathological substrates, several lines of evidence suggest that in disease modifying drug (DMD)-treated MS patients, the higher is the anti-inflammatory effect of the DMD the lower is the progression of brain volume loss, grey matter atrophy and the accumulation of disability.

Areas covered: Magnetic resonance imaging (MRI)-based measurements of inflammation (focal white matter and grey matter lesions) and neurodegeneration (decrease in brain volume, cortical and deep grey matter atrophy) are currently included among the primary or secondary end-points of Phase II and III randomized clinical trials (RCT). This review summarizes literature data on the effects of DMDs on either whole brain or grey matter atrophy emerged from RCT and from post-marketing studies.

Commentary: Taken all together, literature data show that DMDs are capable to reduce significantly brain inflammation and, although with different degrees of effectiveness, to slow down global brain and/or grey matter atrophy progression. Moreover, the comparison between early and delayed treatments clearly points out that the most relevant effects on brain and grey matter atrophy are observed when DMDs are initiated in the very early disease phases.
\end{abstract}

Keywords: Multiple sclerosis, Brain atrophy, Grey matter atrophy, Disease-modifying drugs, Magnetic resonance imaging

\section{Background}

The average rate of brain volume loss per year is significantly higher in multiple sclerosis (MS) patients (range $0.5-1.3 \%$, median $0.7-0.8 \%$ ) than in healthy gender- and age-matched controls (range 0.1-0.3\%, median 0.2\%) [1-4] and it's currently accepted that brain volume decline in MS mainly reflects grey matter (GM) atrophy rather than white matter (WM) loss. Indeed, while WM volume shows a mild reduction during the course of disease, GM volume significantly and progressively decreases [5-13]. Recently, a parenchymal loss of $\geq 0.4 \%$ per year was proposed as "pathological atrophy rate" in MS patients [14].

* Correspondence: paolo.gallo@unipd.it

The Multiple Sclerosis Centre, Department of Neurosciences, DNS, University Hospital of Padua, Via Giustiniani, 5, 35128 Padova, Veneto Region, Italy
GM atrophy, especially cortical atrophy, can be early demonstrated in patients with clinically isolated syndrome suggestive of MS (CIS) and rapidly progresses during the relapsing remitting (RRMS) disease course, becoming particularly evident in the frontal, temporal, and parietal lobes $[5,7,10,11,15-19]$ although in different degrees and with significant regional variation among patients [19-24]. Moreover, deep GM nuclei are site of relevant atrophy as well, i.e., compared to matched healthy subjects, up to $25 \%$ loss of the thalamus volume has been demonstrated in RRMS [24-28].

GM atrophy becomes more widespread and severe in secondary (SPMS) and primary progressive MS (PPMS) [29-37] and, in some patients, may undertake a dramatic acceleration, i.e., up to 14 -fold compared to age-matched healthy individual $[16,36]$. Although PPMS and SPMS show similar extent of total GM atrophy, 
different regional atrophy distribution was described in these two types of MS [34-37] and some correlations between regional WM lesion load and GM atrophy were more often observed in SPMS compared to PPMS, a finding somehow expected given the differences in the WM lesion load that characterize these two MS types. On the other hand, a very weak relationship between WM pathology and GM atrophy is generally found in patients with progressive forms of MS [38], a finding that may be explained with the different rates of evolution of inflammation and neurodegeneration in the more advanced phases of the disease.

All the data above summarized strongly indicate that brain atrophy and cortical and deep GM volume measurements may be useful magnetic resonance imaging (MRI) parameters in predicting MS disease course and progression.

\section{MRI imaging of brain atrophy}

MRI measures of global brain atrophy lack pathological specificity, since they may reflect several changes of WM and GM components that are associated to inflammation and neurodegeneration, such as demyelination, axonal damage, neuronal death, astrocyte and microglia proliferation, as well as physiological fluctuations of the water content. Moreover, the anti-inflammatory DMDs currently used for the treatment of MS differentially act on WM inflammation, thus determining an acceleration of brain volume loss, a phenomenon commonly referred to as "pseudo-atrophy" and assumed to reflect the resolution of inflammation and oedema. This phenomenon may complicate the interpretation of DMD effects, especially in the first two years of therapy.

Measurements of percentage brain volume change (PBVC) and brain parenchymal fraction (BPF) over time are among the best-studied and more used methods for quantifying neurodegeneration in MS. Indeed, the majority of the clinical trials have incorporated BPF or PBVC as a secondary outcome measure of disease progression. PBVC can be obtained by means of the Structural Image Evaluation Using Normalization of Atrophy (SIENA) [39] and its cross-sectional version SIENAX [40], both included in FSL suite [41, 42], i.e., the most used methods to extract brain and skull images from the single whole-head input data. These softwares allow tissue-type segmentation, with partial volume estimation, to calculate the total volume of brain tissue and separate estimates of total GM, deep and cortical GM, and WM volumes [43]. BPF is measured as the ratio between the volume of $\mathrm{WM}+\mathrm{GM}$ and the total intracranial volume $\mathrm{WM}+\mathrm{GM}+$ ventricular CSF. A meta-analysis of 13 clinical trials - including more than 13.500 RRMS patients and in which brain atrophy was measured as PBVC [44] or BPF [45] - showed that treatment effects on disability progression over two years correlated with the effects observed on both brain atrophy $(p=0.001)$ and T2 lesion volume $(p<0.001)$ [46].

Other automated methods are currently available for WM and GM segmentation, that allow the assessment of the total cerebral GM volume, the volumes of deep and cortical GM, as well as the estimation of regional cortical GM volumes [40, 47, 48]. The results of these automated methods are quite reproducible [40, 49]. BPF can be also obtained from Freesurfer and ANTs pipelines or any software providing brain four-tissue segmentation as FSL [43] or SPM [50]. Cortical thickness (CTh) can be calculated with different software tools as Freesurfer, which includes a surface-based method [51], or the more recent ANTs with its registration-based DiRECT algorithm [52, 53].

\section{GM atrophy and disability}

A strong association between physical disability (as measured by means of Expanded Disability Status Scale (EDSS) or timed 25-ft walk (T25FW)) and total, regional and cortical GM volume has been described with consistent agreement among studies. These associations become more remarkable with disease progression from CIS to SPMS. [54-63]. Particularly worth of interest are studies that have demonstrated an association between cerebellar GM loss and the degree of disability in the cerebellar functional system of EDSS [60, 64]. Furthermore, physical disability correlates with both cortical thinning of the frontal, temporal and parietal lobes [29, $30,65,66]$ and with thalamic atrophy [26-28]. In addition, global GM [61, 62, 65-67] and thalamic atrophy $[28,55]$ have been found to predict EDSS score up to $15-20$ years after diagnosis.

Several studies have pointed out a correlation between GM loss in the spinal cord and physical disability and disease duration [68-78]. Indeed, spinal cord atrophy was described in the early MS stages $[69,70,74]$ but was much more pronounced in PPMS and SPMS [76, 77], whereas spinal GM volume inversely correlated with physical disability (measured with EDSS, T25FW, and 9Hole Peg Test scores) in patients with CIS suggestive of MS, and was more predictive for EDSS or Multiple Sclerosis Functional Composite (MSFC) scores that others MRI parameters [68-70, 75-78].

Correlations between cognitive impairment and regional, cortical and total GM volume have also been demonstrated with significant agreement among studies [79-87]. Moreover, associations between specific cognitive domains and various quantitative GM measures (such as thalamic volume, cortical thickness and total GM volume) were found to be strong independent predictors of cognitive decline [23, 26, 34, 84, 87, 88]. 
In summary, brain atrophy and GM (cortical and deep) loss constitute a clinically relevant aspect of MS pathology since the very early disease phases, and, given their association with physical and cognitive disability, should be definitely considered not only a surrogate marker of treatment efficacy, but rather a primary target of DMDs, especially when the treatment is aimed at reducing disability progression.

\section{Effects of disease-modifying drugs on brain and GM atrophy \\ Glatiramer acetate}

The effect of early versus delayed glatiramer acetate (GA) treatment on brain atrophy was analyzed in the open-label phase of the PreCISe trial $[89,90]$, in which CIS patients with unifocal manifestations and $\geq 2 \mathrm{WM}$ T2-lesions were randomized to receive glatiramer acetate $20 \mathrm{mg} /$ day (early-treatment, $n=198$ ) or placebo (delayed-treatment, $n=211$ ) for 36 months or until conversion to clinically definite MS, followed by open-label GA treatment for two years. Early GA treatment was associated to less brain atrophy: PBVC from baseline to the last observed values, adjusted for study exposure, was significantly lower with early GA treatment compared with delayed treatment $(-0.99 \%$ vs. $-1.28 \%, p=0.02)$, with a treatment effect of $28 \%$. Mean PBVC in early GA treated patients ranged between -0.41 in the first year and -0.50 in the fifth year, i.e., values only slightly higher compared to PBVC observed in healthy subjects [91].

These findings are particularly worth of interest since a previous multicentre, randomized, double blind, placebo controlled study in RRMS patients having longer disease duration, failed to demonstrate any impact of GA on brain atrophy [92]. This apparent discrepancy further points out the importance of early treatment. However, other possible explanations of these findings might be the short duration of the follow-up and the application of a not normalized, semi-automated MRI technique (OLD) to analyse brain atrophy. Indeed, a subsequent reanalysis of the same data by means of the fully automated, normalized SIENA method [93], while disclosing similar PBVC average value for both OLD and SIENA techniques, disclosed standard deviations much lower with SIENA. These observations highlight the risk for low reproducibility of not normalized and semiautomated MRI measures for the assessment of brain atrophy and suggest caution when interpreting brain atrophy data.

More recently, in a three year study aimed at analysing efficacy and safety of $40 \mathrm{mg}$ GA three-times-weekly in RRMS, patients that were early treated with GA showed significantly smaller changes in GM volume $(p=0.015)$ compared to patients that were treated with placebo for one year before starting active treatment [94].

\section{Interferon beta}

RRMS patients treated for two years with once weekly intramuscular interferon beta (IFN $\beta$ ) in the MSCRG phase III trial showed significantly less GM atrophy compared with placebo, during year two after treatment initiation [45]. No change in WM atrophy was observed. In this study, the risk of sustained disability progression in IFN $\beta$-treated patients was significantly associated with GM, but not WM, atrophy [95]. Data about the effects of high-dose high-frequency interferon beta 1a (IFN $\beta 1 \mathrm{a})$ on brain parenchymal fraction (BPF) loss can be deduced from the CARE-MS-I and CARE-MS-II trials. In the study CARE-MS-I (alemtuzumab versus IFN $\beta 1$ a as first-line treatment for RRMS) the effect of alemtuzumab on BPF was compared to that of high-dose highfrequency sub-cutis IFNb $\beta 1$ a. Median brain volume loss during the two-years of the core study was -1.49 in the IFNb1a cohort $(-0.94$ in the first year) and -0.87 in the alemtuzumab cohort (-0.59 in the first year) [96]. In the CARE MS-II study (a randomized, controlled, 2-years study on alemtuzumab for patients with RRMS after unsuccessful disease-modifying therapy) [97] the effect of both drugs in slowing down brain volume loss was more pronounced. Indeed, patients treated with high-dose high-frequency IFNb $\beta 1$ a had a $-0.81 \%$ reduction in BPF $(-0.54$ in the first year) versus $-0.61 \%$ of alemtuzumab treated patients. Thus, only in the CARE-MS-II IFN $\beta 1$ a was found to positively impact on brain atrophy. The differences observed between these two studies can be explained with the substantial differences in clinical and demographic characteristics of the patient populations.

To reduce the confounding effect of pseudo-atrophy phenomenon in the evaluation of brain atrophy, in a four-years longitudinal study, we investigated the progression of cortical atrophy in RRMS patients treated with IFN 31 a or GA. Although both drugs were found to decrease the rate of cortical atrophy, a trend in favour of high-dose, high-frequency sub-cutis IFN $\beta 1$ a was noticed [98].

In a study conducted in a small number of RRMS patients, IFN $\beta-1 \mathrm{a} 44 \mu \mathrm{g}$ SC tiw determined a reduction in whole brain and GM tissue volume during the first three months of therapy (mean change; $-0.95 \% ; p=0.030$, $-1.52 \% ; p=0.004$, respectively), suggesting a short-term treatment-induced pseudoatrophy effect, further confirming that the pseudoatrophy effect appears very early as the result of the resolution of inflammation following treatment initiation with interferon $\beta-1 \mathrm{a} 44 \mu \mathrm{g}$ SC tiw [99].

More recently, we have further investigated the effect of IFN $\beta 1$ a on cortical thickness (CTh) in RRMS patients. We performed a four year follow-up study of CTh in a group of 30 IFN 31 a (high-dose high-frequency)-responders RRMS patients (19 females, 11 males) treated 
for a mean period of 4 years with low and stable degrees of disability (mean EDSS $=1.5 \pm 1.0$ ) and very low annualized relapse rate (mean $0.2 \pm 0.47$ year) before study entry. MRI was done at enrolment and then yearly for 4 years. CTh was measured by means of Freesurfer on 3D-T1-MPRAGE images. The mean loss of global CTh at the end of the 4 year follow-up was $1.06 \pm 2.05 \%$, a value equal to that observed in age-matched normal control individuals, thus confirming that a significant slow-down in cortical GM loss can be observed in patients having a good clinical (anti-inflammatory) response to high-dose high-frequency IFN $\beta 1 \mathrm{a}$ [100].

\section{Teriflunomide}

RRMS patients treated with teriflunomide in the TEMSO Study [101] showed a significant decrease in \%BPF compared to placebo, independently from prior DMD treatments, with no significant pseudoatrophy effect. Indeed, after two years of therapy, teriflunomidetreated naïve patients lost $0.93 \%$ BPF against $1.12 \%$ of placebo-treated subjects $(p=0.01)$, while patients coming from previous DMD therapies lost $0.73 \%$ vs $1.51 \%$ $(p=0.001)$.

In a subsequent blinded independent analysis of TEMSO MRI data, the median annualized PBVC from baseline to week 48 was calculated by means of SIENA. PBVC was lower for both teriflunomide groups versus placebo at month 12 (reductions of $34.4 \%$ with teriflunomide $7 \mathrm{mg}, p=0.0011$, and $36.9 \%$ with teriflunomide $14 \mathrm{mg}, p=0.0001$ ) and month 24 (reductions of $27.6 \%$ with teriflunomide $7 \mathrm{mg}, p=0.0019$, and $30.6 \%$ with teriflunomide $14 \mathrm{mg}, \mathrm{p}=0.0001$ ) [102], thus confirming a significant effect of this drug in slowing-down PBVC loss. These findings are particularly interesting considering the relative modest effect of teriflunomide on the MRI parameters of WM inflammation that suggests a possible direct effect of teriflunomide on grey matter atrophy.

\section{Dimethyl fumarate}

Reductions in brain atrophy with dimethyl fumarate (DMF) in comparison to placebo did not reach statistical significance in the CONFIRM study [103], while in the DEFINE study a relative reduction in the progression of brain atrophy from baseline to year 2 (21\% reduction; $p=0.0449)$ and from month 6 to year 2 (30\% reduction; $p=0.0214$ ) was observed and was statistically significant [104].

Recently, a retrospective analysis [105] in a small group of 20 RRMS patients followed for up to 1 year, the DMF group showed a lower rate of whole brain atrophy compared to no-DMT group (PBVC: $-0.37 \pm 0.49 \%$ vs. $-1.04 \pm 0.67 \%, p=0.005)$. Although the DMF-treated group had less change in putamen volume $(-0.06 \pm 0.22$ vs. $-0.32 \pm 0.28 \mathrm{ml}, p=0.02$ ), no significant on-study differences between groups in caudate, globus pallidus, thalamus, total deep gray matter volume, T2 lesion volume, EDSS, or T25FW (all $p>0.20$ ) were demonstrated, probably because of the very low number of patients enrolled in the study.

\section{Fingolimod}

In the two Phase III studies FREEDOMS and FREEDOMS II [106, 107], fingolimod was found to reduce the PBV loss in RRMS patients by $36 \%(p<0.001)$ and $33 \%(p=0.0002)$, respectively. Whether this effect on PBV was mediated through the anti-inflammatory effects of the drug on WM focal inflammatory damage or was primarily a direct effect on the diffuse neurodegenerative damage, has been investigated in a post-hoc analysis in which patients with no evidence of focal disease activity from the two studies were pooled [108]. This analysis disclosed that fingolimod was capable to reduce significantly PBV change by $65.5 \%$ over 12 months (fingolimod vs. placebo: -0.16 vs $-0.45 ; p=0.001)$ and by $48.2 \%$ over 24 months $(-0.42$ vs. $-0.81 ; p=0.004)$. An absolute difference in PBV change of $-0.27 \%(p<0.001)$ in favour of fingolimod vs. placebo over 24 months was still evident in the pooled intention to treat (ITT) population, after adjusting for active lesions and on-study relapses. The regression model suggested that $54 \%(-0.27 \% /-0.51 \%)$ of the effect of fingolimod on PBV change was independent of its effects on visible focal WM damage. Thus, the effect of fingolimod on diffuse damage seems partly independent of its anti-inflammatory effect, suggesting that this drug positively affects both the inflammatory and the neurodegenerative components of MS.

In a post hoc analysis of studies assessing fingolimod efficacy, brain volume loss was found to correlate with disease severity at baseline and disease activity during the course of the study [109]. This supports the concept that inflammatory activity, lesion load, and number of relapses contribute to atrophy, and that treatment of this activity has a beneficial effect on atrophy rates.

\section{Natalizumab}

The controversial available data on the effects of natalizumab on brain atrophy can be primarily explained with the strong anti-inflammatory effect (i.e., marked pseudoatrophy effect) of this monoclonal antibody and by the clinical and radiological features of the majority of the patients treated with this drug (i.e., RRMS patients with very high disease activity, frequently coming from firstline treatment failure).

Indeed, in a recent study on sixty-two MS patients [110], having a mean age of $34.7 \pm 8.3$ and a mean disease duration of $10.4 \pm 6.6$ years, the presence of gadolinium enhancing lesions at baseline was associated 
with a strong pseudoatrophy effect. Indeed, the larger PBV decrease $(p=0.005)$ were observed in the first $(p=0.024)$ and second year $(p=0.019)$ but not in the third year $(p=0.863)$. On the contrary, the decrease in PBV in patients having no evidence of active brain inflammation was about $1 \%$ in the two years, a figure very close to that of normal subjects. Thus, baseline inflammation of RRMS patients with very high disease activity strongly affects brain volume measures up to 24 months after natalizumab initiation.

A marked pseudoatrophy effect of natalizumab therapy was confirmed in a 18-month study where the PBV of natalizumab-treated patients was found to dramatically decrease especially in the first 12 months of treatment [111].

In a recently published study aimed at investigating whether cerebrospinal fluid (CSF) markers of inflammation or neurodegeneration were associated with PBV change in natalizumab-treated MS and whether this change was reflected in non-lesional WM metabolites (analysed by proton magnetic resonance spectroscopy, ${ }^{1} \mathrm{H}$-MRS), twenty-five natalizumab-treated RRMS were followed for 3 years. The mean decline in PBV was 3\% at the 3-year follow-up, but mean ${ }^{1} \mathrm{H}$-MRS metabolite levels in non-lesional WM were unchanged. Interestingly, CSF levels of neurofilaments and tau at baseline correlated negatively with PBV change over 3 years $(r=-0.564, p=0.012$, and $r=-0.592, p=0.010$, respectively), suggesting their possible use for evaluating treatment response in MS [112].

In order to study the effect of natalizumab on GM atrophy avoiding the marked pseudo-atrophy effect of the drug on brain parenchymal volume, we analysed the cortical thickness of RRMS patients treated with natalizumab for up to four years. Thirty patients non-responder to IFN $\beta$, having had a mean annualized relapse rate of $1.5 \pm 1.0$ (range 1-4) in the year prior to natalizumab initiation, evidence of disease activity at brain MRI and mean EDSS score of $3.0 \pm 1.6$ were enrolled in the study. CTh was measured by Freesurfer on 3DT1 images obtained at study entry and then annually for 4 years. At the end of the study, natalizumab-treated patients had a mean loss of CTh of $2.09 \pm 3.3 \%$, corresponding to mean annual CTh loss of $0.5 \%$, a value higher compared to age-matched normal controls, but significantly lower compared to untreated MS patients [100]. Our finding are particularly interesting since they indicate that, once reached EDSS 3.0 (i.e., a disability milestone that marks the entry in the progressive disease phase) the impact of anti-inflammatory therapies on neurodegeneration becomes less pronounced and may be not significant. This further suggests the importance of early therapeutic intervention with second line drugs in patients with poor response to first line therapies.

\section{Alemtuzumab}

As above described, in RRMS patients treated with alemtuzumab in the CARE-MS-I RCT the mean percentage of BPF loss after two years was -0.87 against -1.49 of the patients treated with high-dose high frequency sub-cutis IFN $\beta$. At the end of the extension study (core study + extension $=6$ years) the BPF loss was $-1.43 \%$, corresponding to a mean loss of $-0.23 \% / y e a r$, comparable to the mean loss observed in normal individuals. This extraordinary result was confirmed in the CARE-MS-II RCT: after two years the mean percentage of BPF loss was $-0.62 \%$ in alemtuzumab-treated patients and -0.82 in IFN $\beta$-treated patients. At the end of the extension study, alemtuzumab-treated patients lost a mean percentage of BPF of -0.95 , corresponding to a mean annual loss of $-0.16 \%$ [113].

\section{Daclizumab}

In a retrospective analysis aimed at determining the effect of daclizumab on brain atrophy, 26 MS patients treated for a median period of 4.3 years with daclizumab were compared to a control group of 44 patients treated with other DMD (predominantly IFN $\beta$ ). Supratentorial brain volume declined by $5.17 \mathrm{ml}$ per year (95\% confidence limits: $3.58-6.77)$ in the DMD group and by $3.72 \mathrm{ml}(p=0.01)$ in the daclizumab group. The rate of ventricular enlargement decreased from 1.26 to $0.42 \mathrm{ml}$ per year $(p<0.001)$. Focused analysis suggested that reduction in the rate of GM atrophy could explain the results [114].

\section{Ocrelizumab}

In the trial ORATORIO the effect of ocrelizumab (antiCD20 humanized antibody) on disability progression (primary endpoint) was analysed in the primary progressive form of MS. Among the secondary MRI endpoints, the adjusted mean PBVC from week 24 to week 120 (fourth secondary endpoint) was lower with ocrelizumab than with placebo $(-0.90$ vs. -1.09$)$ and the difference reached the significance $(p=0.02)$ [115].

In the trials OPERA I and OPERA II (ocrelizumab versus high-dose high frequency sub-cutis IFN $\beta 1 \mathrm{a}$ in RRMS), despite the extraordinary effects of the drugs on clinical and MRI-inflammatory endpoints, the differences in the \% PBVC from week 24 to week 96 between the ocrelizumab group and the IFN $\beta$ group were nonconfirmatory in the OPERA I trial (nominal $p=0.004$ ) and non-significant in the OPERA II trial (nominal $p=0.09)$ [116]. Although the findings were nonconfirmatory as a result of failure of the hierarchical analysis, the percentages of patients who had no evidence of disease activity were higher with ocrelizumab than with IFN $\beta 1 \mathrm{a}$ in both trials. 


\section{Cladribine}

An exploratory analysis on the cladribine tablets treating multiple sclerosis orally (CLARITY) study (phase-3, double-blind, placebo-controlled, multicenter trial in patients with RMS assessing the effects of cladribine tablets given annually over 2 years) [117] disclosed that cladribine significantly reduced brain atrophy in comparison with placebo treatment, with residual rates in treated patients being close to the physiological rates [118]. Indeed, compared with placebo $(-0.70 \% \pm 0.79)$, the annualized percentage brain volume change (PBVC/ y) was reduced in patients treated with cladribine tablets $3.5 \mathrm{mg} / \mathrm{kg}(-0.56 \% \pm 0.68, p=0.010)$ and $5.25 \mathrm{mg} / \mathrm{kg}$ $(-0.57 \% \pm 0.72, p=0.019)$. After adjusting for treatment group, PBVC/y showed a significant correlation with the cumulative probability of disability progression $(\mathrm{HR}=0.67,95 \% \mathrm{CI}=0.571,0.787 ; p<0.001)$, with patients with lower PBVC/y showing the highest probability of remaining free from disability progression at 2 years and vice versa. Since cladribine crosses the blood brain barrier, it might be hypothesized that this drug acts not only on focal WM inflammation, but also on the diffuse brain, including cortical, tissue damage and neurodegeneration in RRMS.

\section{Conclusions}

This review highlights that 1) compared to no treatment, all DMDs reduce the rate of brain volume loss and/or GM atrophy in RRMS, 2) the early treatment generally shows a more relevant impact on brain atrophy measures compared to late treatment, 3) second line therapies generally have a more significant and long lasting impact on MRI metrics of either brain or GM atrophy. Figure 1 reports the brain volume changes observed with some currently used DMDs and clearly shows that DMDs lessen the progression of brain atrophy observed in MS patients to values similar to those observed in normal individuals. Of course, a direct comparison between drugs is hampered by substantial differences among the experimental design of the trials (including patient selection, clinical and MRI parameters).

This review further confirms that the current attitude of treating RRMS with DMD in very early disease phases, possibly since clinical onset, is correct and has a strong rationale also in preventing or slowing down neurodegeneration and disability progression. Moreover, in as much as global brain volume loss and grey matter damage remain MRI parameters not routinely evaluated, the discontinuation of therapy in patients judged to be "clinically" stable for prolonged period of time on the base of the relapse rate and/or rough MRI parameters of WM damage should be considered with caution.

Increasing evidence suggests that MRI metrics of brain atrophy should be definitely considered not only surrogate markers of treatment efficacy, but rather a primary target of DMDs, especially when the treatment is aimed at reducing disability progression. However, further studies aimed at investigating the mechanisms of grey matter damage and how DMDs may positively modify this critical aspect of MS pathology are needed.

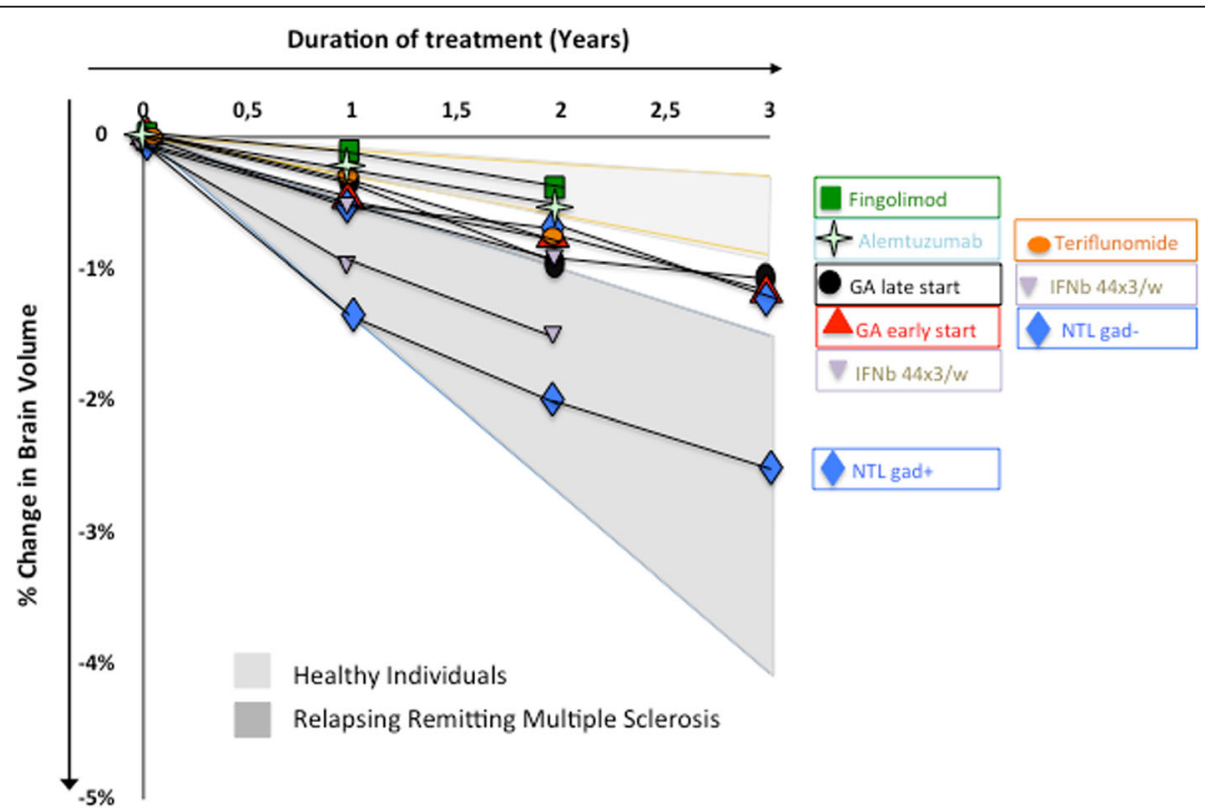

Fig. 1 Percent changes in brain volume in multiple sclerosis patients under treatment for two or three years with disease modifying drugs in Phase III Randomized Clinical Trials or observational studies. The estimated ranges of brain volume loss for healthy individuals and relapsing remitting multiple sclerosis are indicated with different shades of grey 


\section{Acknowledgements}

None.

\section{Funding}

NA

\section{Availability of data and materials}

NA

\section{Authors' contributions}

All Authors have contributed to manuscript preparation. All authors read and approved the final manuscript.

\section{Ethics approval and consent to participate NA}

\section{Consent for publication}

NA

\section{Competing interests}

During the past 3 years, Professor P. Gallo has had a financial relationship (lecturer, member of advisory boards and/or consultant or investigator) with Biogen Italy, TEVA, Merck-Serono, Novartis Farma, Sanofi-Genzyme, Roche and Almirall. Dr. A. Favaretto has received funding for travel and speaker honoraria in the last 3 years from Teva, Novartis, Biogen Italy, and Genzyme. A. Lazzarotto, M. Margoni, and D. Poggiali have nothing to disclose.

\section{Publisher's Note}

Springer Nature remains neutral with regard to jurisdictional claims in published maps and institutional affiliations.

Received: 10 August 2017 Accepted: 14 December 2017

Published online: 29 January 2018

\section{References}

1. Kalkers NF, Ameziane N, Bot JC, Minneboo A, Polman CH, Barkhof F. Longitudinal brain volume measurement in multiple sclerosis: rate of brain atrophy is independent of the disease subtype. Arch Neurol. 2001;59:1572-6.

2. Giorgio A, Battaglini M, Smith SM, De Stefano N. Brain atrophy assessment in multiple sclerosis: importance and limitations. Neuroimaging Clin N Am. 2008; 18:675-86

3. Vågberg $M$, Lindqvist $T$, Ambarki $K$, Warntjes JB, Sundström $P$, Birgander $R$, Svenningsson A. Automated determination of brain parenchymal fraction in multiple sclerosis. AJNR Am J Neuroradiol. 2013;34(3):498-504.

4. Vollmer T, Signorovitch J, Huynh L, Galebach P, Kelley C, DiBernardo A Sasane RU. The natural history of brain volume loss among patients with multiple sclerosis: a systematic literature review and meta-analysis. J Neurol Sci. 2015:357(1-2):8-18.

5. Chard DT, Griffin CM, Parker GJ, Kapoor R, Thompson AJ, Miller DH. Brain atrophy in clinically early relapsing-remitting multiple sclerosis. Brain. 2001 125:327-37

6. Chard DT, Griffin CM, Rashid W, Davies GR, Altmann DR, Kapoor R, Barker GJ, Thompson AJ, Miller DH. Progressive grey matter atrophy in clinically early relapsing-remitting multiple sclerosis. Mult Scler. 2004:10:387-91.

7. Sailer M, Fischl B, Salat D, Tempelmann C, Schönfeld MA, Busa E, Bodammer $\mathrm{N}$, Heinze HJ, Dale A. Focal thinning of the cerebral cortex in multiple sclerosis. Brain. 2003;126:1734-44.

8. Tiberio M, Chard DT, Altmann DR, Davies G, Griffin CM, Rashid W, SastreGarriga J, Thompson AJ, Miller DH. Gray and white matter volume changes in early RRMS: a 2-year longitudinal study. Neurology. 2005;64:1001-7.

9. Audoin B, Davies GR, Finisku L, Chard DT, Thompson AJ, Miller DH. Localization of grey matter atrophy in early RRMS: a longitudinal study. J Neurol. 2006;253:1495-501.

10. Calabrese M, Atzori M, Bernardi V, Morra A, Romualdi C, Rinaldi L, McAuliffe MJ, Barachino L, Perini P. Fischl B, Battistin L, Gallo P. Cortical atrophy is relevant in multiple sclerosis at clinical onset. J Neurol. 2007;254:1212-20.

11. Calabrese M, Rinaldi F, Mattisi I, Grossi P. Favaretto A, Atzori M, Bernardi V, Barachino L, Romualdi C, Rinaldi L, Perini P, Gallo P. Widespread cortical thinning characterizes patients with MS with mild cognitive impairment. Neurology. 2010;74:321-8.
12. Ramasamy DP, Benedict RH, Cox JL, Fritz D, Abdelrahman N, Hussein S, Minagar A, Dwyer MG, Zivadinov R. Extent of cerebellum, subcortical and cortical atrophy in patients with MS: a case-control study. J Neurol Sci. 2009; 282:47-54.

13. Henry RG, Shieh M, Okuda DT, Evangelista A, Gorno-Tempini ML, Pelletier D. Regional grey matter atrophy in clinically isolated syndromes at presentation. J Neurol Neurosurg Psychiatry. 2008;79:1236-44.

14. De Stefano N, Stromillo ML, Giorgio A, Bartolozzi ML, Battaglini M, Baldini M, Portaccio E, Amato MP, Sormani MP. Establishing pathological cut-offs of brain atrophy rates in multiple sclerosis. J Neurol Neurosurg Psychiatry. 2016:87:93-9.

15. Calabrese M, Rinaldi F, Mattisi I, Bernardi V, Favaretto A, Perini P, Gallo P. The predictive value of gray matter atrophy in clinically isolated syndromes. Neurology. 2011;77:257-63.

16. Battaglini M, Giorgio A, Stromillo ML, Bartolozzi ML, Guidi L, Federico A, De Stefano N. Voxel-wise assessment of progression of regional brain atrophy in relapsing remitting multiple sclerosis. J Neurol Sci. 2009:282:55-60.

17. Sepulcre J, Sastre-Garriga J, Cercignani M, Ingle GT, Miller DH, Thompson AJ. Regional gray matter atrophy in early primary progressive multiple sclerosis: a voxel-based morphometry study. Arch Neurol. 2006;63:1175-80.

18. Ceccarelli A, Rocca MA, Pagani E, Colombo B, Martinelli V, Comi G, Filippi M A voxel-based morphometry study of grey matter loss in MS patients with different clinical phenotypes. Neurolmage. 2008;42:315-22.

19. Sicotte NL, Kern KC, Giesser BS, Arshanapalli A, Schultz A, Montag M, Wang $\mathrm{H}$, Bookheimer SY. Regional hippocampal atrophy in multiple sclerosis. Brain 2008:131:1134-41.

20. Tao G, Datta S, He R, Nelson F, Wolinsky JS, Narayana PA. Deep gray matter atrophy in multiple sclerosis: a tensor based morphometry. J Neurol Sci. 2009;282:39-46

21. Anderson VM, Fisniku LK, Khaleeli Z, Summers MM, Penny SA, Altmann DR, Thompson AJ, Ron MA, Miller DH. Hippocampal atrophy in relapsingremitting and primary progressive MS: a comparative study. Mult Scler. 2010;16:1083-90.

22. Audoin B, Zaaraoui W, Reuter $F$, et al. Atrophy mainly affects the limbic system and the deep grey matter at the first stage of multiple sclerosis. J Neurol Neurosurg Psychiatry. 2010:81:690-5.

23. Audoin B, Zaaraoui W, Reuter F, Rico A, Malikova I, Confort-Gouny S, Cozzone PJ, Pelletier J, Ranjeva JP. Subcortical atrophy and cognition: sex effects in multiple sclerosis. Neurology. 2012;79:1754-61.

24. Cifelli A, Arridge M, Jezzard P, Esiri MM, Palace J, Matthews PM. Thalamic neurodegeneration in multiple sclerosis. Ann Neurol. 2002;52:650-3.

25. Carone DA, Benedict RH, Dwyer MG, Cookfair DL, Srinivasaraghavan B, Tjoa CW, Zivadinov R. Semi-automatic brain region extraction (SABRE) reveals superior cortical and deep gray matter atrophy in MS. Neurolmage. 2006:29:505-14.

26. Houtchens MK, Benedict RH, Killiany R, Sharma J, Jaisani Z, Singh B, Weinstock-Guttman B, Guttmann CR, Bakshi R. Thalamic atrophy and cognition in multiple sclerosis. Neurology. 2007;69:1213-23.

27. Mesaros S, Rocca MA, Absinta M, Ghezzi A, Milani N, Moiola L, Veggiotti $P$, Comi G, Filippi M. Evidence of thalamic gray matter loss in pediatric multiple sclerosis. Neurology. 2008;70:1107-12.

28. Rocca MA, Mesaros S, Pagani E, Sormani MP, Comi G, Filippi M. Thalamic damage and long-term progression of disability in multiple sclerosis. Radiology. 2010;257:463-9.

29. Chen JT, Narayanan S, Collins DL, Smith SM, Matthews PM, Arnold DL. Relating neocortical pathology to disability progression in multiple sclerosis using MRI. Neurolmage. 2004;23:1168-75.

30. Pagani E, Rocca MA, Gallo A, Rovaris M, Martinelli V, Comi G, Filippi M. Regional brain atrophy evolves differently in patients with multiple sclerosis according to clinical phenotype. AJNR Am J Neuroradiol. 2005;26:341-6.

31. Tedeschi G, Lavorgna L, Russo P, Prinster A, Dinacci D, Savettieri G, Quattrone A, Livrea P, Messina C, Reggio A, Bresciamorra V, Orefice G, Paciello M, Brunetti A, Coniglio G, Bonavita S, Di Costanzo A, Bellacosa A, Valentino P, Quarantelli M, Patti F, Salemi G, Cammarata E, Simone IL, Salvatore $\mathrm{M}$, Bonavita $\mathrm{V}$, Alfano B. Brain atrophy and lesion load in a large population of patients with multiple sclerosis. Neurology. 2005;65:280-5.

32. Benedict RH, Bruce JM, Dwyer MG, Abdelrahman N, Hussein S, WeinstockGuttman B, Garg N, Munschauer F, Zivadinov R. Neocortical atrophy, third ventricular width, and cognitive dysfunction in multiple sclerosis. Arch Neurol. 2006;63:1301-6.

33. Benedict RH, Bruce JM, Dwyer MG, Abdelrahman N, Hussein S, WeinstockGuttman B, Garg N, Munschauer F, Zivadinov R. Association of regional gray 
matter volume loss and progression of white matter lesions in multiple sclerosis - a longitudinal voxel-based morphometry study. Neurolmage. 2009;45:60-7.

34. Riccitelli G, Rocca MA, Pagani E, Rodegher ME, Rossi P, Falini A, Comi G, Filippi M. Cognitive impairment in multiple sclerosis is associated to different patterns of gray matter atrophy according to clinical phenotype. Hum Brain Mapp. 2011;32:1535-43.

35. Roosendaal SD, Bendfeldt K, Vrenken H, Polman CH, Borgwardt S, Radue EW, Kappos L, Pelletier D, Hauser SL, Matthews PM, Barkhof F, Geurts JJ. Grey matter volume in a large cohort of MS patients: relation to MRI parameters and disability. Mult Scler. 2011;17:1098-106.

36. Fisher E, Lee JC, Nakamura K, Rudick RA. Gray matter atrophy in multiple sclerosis: a longitudinal study. Ann Neurol. 2008;64:255-65.

37. Ceccarelli A, Rocca MA, Valsasina P, Rodegher M, Pagani E, Falini A, Comi G, Filippi M. A multiparametric evaluation of regional brain damage in patients with primary progressive multiple sclerosis. Hum Brain Mapp. 2009;30:3009-19.

38. Steenwijk MD, Daams M, Pouwels PJ, Balk LJ, Tewarie PK, Killestein J, Uitdehaag BM, Geurts JJ, Barkhof F, Vrenken H. What explains gray matter atrophy in long-standing multiple sclerosis? Radiology. 2014;272:832-42.

39. Smith S, Zhang Y, Jenkinson M, Matthews PM, De Stefano N. SIENA: Single and multiple time point brain atrophy analysis. Neurolmage. 2001;13:250

40. Smith SM, Zhang Y, Jenkinson M, Chen J, Matthews PM, Federico A, De Stefano N. Accurate, robust, and automated longitudinal and cross-sectional brain change analysis. Neurolmage. 2002;17:479-89.

41. Smith SM, Jenkinson M, Woolrich MW, Beckmann CF, Behrens TE, JohansenBerg H, Bannister PR, De Luca M, Drobnjak I, Flitney DE, Niazy RK, Saunders J, Vickers J, Zhang Y, De Stefano N, Brady JM, Matthews PM. Advances in functional and structural MR image analysis and implementation as FSL. Neurolmage. 2004;23:S208-19.

42. Jenkinson M, Beckmann CF, Behrens TE, Woolrich MW, Smith SM. FSL. Neurolmage. 2012;62:782-90

43. Zhang $Y$, Brady M, Smith S. Segmentation of brain MR images through a hidden Markov random field model and the expectation-maximization algorithm. IEEE Trans Med Imaging. 2001;20:45-57.

44. Smith SM, De Stefano N, Jenkinson M, Matthews PM. Normalized accurate measurement of longitudinal brain change. J Comput Assist Tomogr. 2001; 25:466-75.

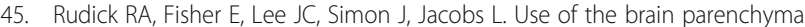
fraction to measure whole brain atrophy in relapsing-remitting MS. Multiple Sclerosis Collaborative Research Group. Neurology. 1999:53:1698-170.

46. Sormani MP, Arnold DL, De Stefano N. Treatment effect on brain atrophy correlates with treatment effect on disability in multiple sclerosis. Ann Neurol. 2014;75:43-9.

47. Ashburner J, Friston KJ. Voxel-based morphometry-the methods. Neurolmage. 2000;11(6 Pt 1):805-21.

48. Fischl B, Dale AM. Measuring the thickness of the human cerebral cortex from magnetic resonance images. Proc Natl Acad Sci U S A. 2000;97:11050-5.

49. Jasperse B, Valsasina P, Neacsu V, Knol DL, De Stefano N, Enzinger C, Smith SM, Ropele S, Korteweg T, Giorgio A, Anderson V, Polman CH, Filippi M, Miller DH, Rovaris M, Barkhof F, Vrenken H. Magnetic imaging in multiple sclerosis (MAGNIMS) study group. Intercenter agreement of brain atrophy measurement in multiple sclerosis patients using manually-edited SIENA and SIENAX. J Magn Reson Imaging. 2007;26:881-5.

50. Ashburner J, Friston KJ. Unified segmentation. Neurolmage. 2005:26:839-51.

51. Fischl B. FreeSurfer. Neurolmage. 2012;62:774-81.

52. Das SR, Avants BB, Grossman M, Gee JC. Registration based cortical thickness measurement. Neurolmage. 2009;45:867-79.

53. Tustison NJ, Cook PA, Klein A, Song G, Das SR, Duda JT, Kandel BM, van Strien N, Stone JR, Gee JC, Avants BB. Large-scale evaluation of ANTs and FreeSurfer cortical thickness measurements. Neurolmage. 2014;99:166-79.

54. Dalton CM, Chard DT, Davies GR, Miszkiel KA, Altmann DR, Fernando K, Plant GT, Thompson AJ, Miller DH. Early development of multiple sclerosis is associated with progressive grey matter atrophy in patients presenting with clinically isolated syndromes. Brain. 2004;127:1101-7.

55. Fisniku LK, Chard DT, Jackson JS, Anderson VM, Altmann DR, Miszkiel KA Thompson AJ, Miller DH. Gray matter atrophy is related to long-term disability in multiple sclerosis. Ann Neurol. 2008:64:247-54.

56. Calabrese M, Romualdi C, Poretto V, Favaretto A, Morra A, Rinaldi F, Perini P, Gallo $P$. The changing clinical course of multiple sclerosis: a matter of gray matter. Ann Neurol. 2013;74:76-83.
57. Pérez-Miralles F, Sastre-Garriga J, Tintoré M, Arrambide G, Nos C, Perkal H, Río J, Edo MC, Horga A, Castilló J, Auger C, Huerga E, Rovira A, Montalban X. Clinical impact of early brain atrophy in clinically isolated syndromes. Mult Scler. 2013;19:1878-86.

58. De Stefano N, Matthews PM, Filippi M, Agosta F, De Luca M, Bartolozzi ML, Guidi L, Ghezzi A, Montanari E, Cifelli A, Federico A, Smith SM. Evidence of early cortical atrophy in MS: relevance to white matter changes and disability. Neurology. 2003;60:1157-62.

59. Sanfilipo MP, Benedict RH, Sharma J, Weinstock-Guttman B, Bakshi R. The relationship betweenwhole brain volumeand disability in multiple sclerosis: a comparison of normalized gray vs. white matter with misclassification correction. Neurolmage. 2005;26:1068-77.

60. Anderson VM, Fisniku LK, Altmann DR, Thompson AJ, Miller DH. MR measures show significant cerebellar gray matter volume loss in multiple sclerosis and are associated with cerebellar dysfunction. Mult Scler. 2009;15: $811-7$.

61. Rudick RA, Lee JC, Nakamura K, Fisher E. Gray matter atrophy correlates with MS disability progression measured with MSFC but not EDSS. J Neurol Sci. 2009:282:106-11.

62. Lavorgna L, Bonavita S, Ippolito D, Lanzillo R, Salemi G, Patti F, Valentino P, Coniglio G, Buccafusca M, Paolicelli D, d'Ambrosio A, Bresciamorra V, Savettieri G, Zappia M, Alfano B, Gallo A, Simone I, Tedeschi G. Clinical and magnetic resonance imaging predictors of disease progression in multiple sclerosis: a nine-year follow-up study. Mult Scler. 2014;20:220-6.

63. Bendfeldt $K$, Hofstetter $L$, Kuster $P$, Traud S, Mueller-Lenke N, Naegelin $Y$, Kappos L, Gass A, Nichols TE, Barkhof F, Vrenken H, Roosendaal SD, Geurts $J$ J, Radue EW, Borgwardt SJ. Longitudinal gray matter changes in multiple sclerosis-differential scanner and overall disease-related effects. Hum Brain Mapp. 2012;33:1225-45.

64. Favaretto A, Lazzarotto A, Poggiali D, Rolma G, Causin F, Rinaldi F, Perini P, Gallo P. MRI-detectable cortical lesions in the cerebellum and their clinical relevance in multiple sclerosis. Mult Scler. 2016;22:494-501.

65. Bakshi R, Benedict RH, Bermel RA, Jacobs L. Regional brain atrophy is associated with physical disability in multiple sclerosis: semiquantitative magnetic resonance imaging and relationship to clinical findings. J Neuroimaging. 2001;11:129-36.

66. Horakova D, Dwyer MG, Havrdova E, Cox JL, Dolezal O, Bergsland N, Rimes B, Seidl Z, Vaneckova M, Zivadinov R. Gray matter atrophy and disability progression in patients with early relapsing remitting multiple sclerosis: a 5year longitudinal study. J Neurol Sci. 2009;282:112-9.

67. Filippi M, Preziosa P, Copetti M, Riccitelli G, Horsfield MA, Martinelli V, Comi G, Rocca MA. Gray matter damage predicts the accumulation of disability 13 years later in MS. Neurology. 2013;81:1759-67.

68. Nijeholt GJ, van Walderveen MA, Castelijns JA, van Waesberghe JH, Polman C, Scheltens P, Rosier PF, Jongen PJ, Barkhof F. Brain and spinal cord abnormalities in multiple sclerosis. Correlation between MRI parameters, clinical subtypes and symptoms. Brain. 1998;121(Pt 4):687-97.

69. Liu C, Edwards S, Gong Q, Roberts N, Blumhardt LD. Three dimensional MRI estimates of brain and spinal cord atrophy in multiple sclerosis. J Neurol Neurosurg Psychiatry. 1999;66:323-30.

70. Brex PA, Leary SM, O'Riordan Jl, Miszkiel KA, Plant GT, Thompson AJ, Miller $\mathrm{DH}$. Measurement of spinal cord area in clinically isolated syndromes suggestive of multiple sclerosis. J Neurol Neurosurg Psychiatry. 2001;70:544-7.

71. Evangelou N, DeLuca GC, Owens T, Esiri MM. Pathological study of spinal cord atrophy in multiple sclerosis suggests limited role of local lesions. Brain. 2005;128:29-34.

72. Gilmore CP, Bo L, Owens T, Lowe J, Esiri MM, Evangelou N. Spinal cord gray matter demyelination in multiple sclerosis - a novel pattern of residual plaque morphology. Brain Pathol. 2006;16:202-8.

73. Gilmore CP, Donaldson I, Bo L, Owens T, Lowe J, Evangelou N. Regional variations in the extent and pattern of grey matter demyelination in multiple sclerosis: a comparison between the cerebral cortex, cerebellar cortex, deep grey matter nuclei and the spinal cord. J Neurol Neurosurg Psychiatry. 2009;80:182-7.

74. Rashid W, Davies GR, Chard DT, Griffin CM, Altmann DR, Gordon R, Thompson AJ, Miller $\mathrm{DH}$. Increasing cord atrophy in early relapsingremitting multiple sclerosis: a 3 year study. J Neurol Neurosurg Psychiatry. 2006;77:51-5.

75. Furby J, Hayton T, Anderson V, Altmann D, Brenner R, Chataway J, Hughes R, Smith K, Miller D, Kapoor R. Magnetic resonance imaging measures of 
brain and spinal cord atrophy correlate with clinical impairment in secondary progressive multiple sclerosis. Mult Scler. 2008;14:1068-75.

76. Rocca MA, Horsfield MA, Sala S, Copetti M, Valsasina P, Mesaros S, Martinelli V, Caputo D, Stosic-Opincal T, Drulovic J, Comi G, Filippi MA. Multicentre assessment of cervical cord atrophy among MS clinical phenotypes. Neurology. 2011;76:2096-102.

77. Lukas C, Sombekke MH, Bellenberg B, Hahn HK, Popescu V, Bendfeldt K, Radue EW, Gass A, Borgwardt SJ, Kappos L, Naegelin Y, Knol DL, Polman CH, Geurts JJ, Barkhof F, Vrenken H. Relevance of spinal cord abnormalities to clinical disability in multiple sclerosis: MR imaging findings in a large cohort of patients. Radiology. 2013;269:542-52.

78. Losseff NA, Webb SL, O'Riordan Jl, Page R, Wang L, Barker GJ, Tofts PS, McDonald WI, Miller DH, Thompson AJ. Spinal cord atrophy and disability in multiple sclerosis. A new reproducible and sensitive MRI method with potential to monitor disease progression. Brain. 1996;119(Pt 3):701-8.

79. Amato MP, Bartolozzi ML, Zipoli V, Portaccio E, Mortilla M, Guidi L, Siracusa G, Sorbi S, Federico A, De Stefano N. Neocortical volume decrease in relapsing-remitting MS patients with mild cognitive impairment. Neurology. 2004;63:89-93.

80. Amato MP, Portaccio E, Goretti B, et al. Association of neocortical volume changes with cognitive deterioration in relapsing-remitting multiple sclerosis. Arch Neurol. 2007;64:1157-61.

81. Morgen K, Sammer G, Courtney SM, Wolters T, Melchior H, Blecker CR, Oschmann P, Kaps M, Vaitl D. Evidence for a direct association between cortical atrophy and cognitive impairment in relapsing-remitting MS. Neurolmage. 2006;30:891-8.

82. Benedict RH, Ramasamy D, Munschauer F, Weinstock-Guttman B, Zivadinov R. Memory impairment in multiple sclerosis: correlation with deep grey matter and mesial temporal atrophy. J Neurol Neurosurg Psychiatry. 2009; 80:201-6

83. Benedict RH, Hulst HE, Bergsland N, Schoonheim MM, Dwyer MG, Weinstock-Guttman B, Geurts JJ, Zivadinov R. Clinical significance of atrophy and white matter mean diffusivity within the thalamus of multiple sclerosis patients. Mult Scler. 2013:19:1478-84.

84. Till C, Ghassemi R, Aubert-Broche B, Kerbrat A, Collins DL, Narayanan S, Arnold DL, Desrocher M, Sled JG, Banwell BL. MRI correlates of cognitive impairment in childhood-onset multiple sclerosis. Neuropsychology. 2011; 25:319-32.

85. Schoonheim MM, Geurts J, Wiebenga OT, De Munck JC, Polman CH, Stam CJ, Barkhof F, Wink AM. Changes in functional network centrality underlie cognitive dysfunction and physical disability in multiple sclerosis. Mult Scler. 2014;20:1058-65.

86. Schoonheim MM, Meijer KA, Geurts JJ. Network collapse and cognitive impairment in multiple sclerosis. Front Neurol. 2015;6:82.

87. Batista S, Zivadinov R, Hoogs M, Bergsland N, Heininen-Brown M, Dwyer MG, Weinstock-Guttman B, Benedict RH. Basal ganglia, thalamus and neocortical atrophy predicting slowed cognitive processing in multiple sclerosis. J Neurol. 2012;259:139-46.

88. Calabrese M, Agosta F, Rinaldi F, Mattisi I, Grossi P, Favaretto A, Atzori M, Bernardi V, Barachino L, Rinaldi L, Perini P, Gallo P, Filippi M. Cortical lesions and atrophy associated with cognitive impairment in relapsingremitting multiple sclerosis. Arch Neurol. 2009;66:1144-50.

89. Comi G, Martinelli V, Rodegher M, Moiola L, Bajenaru O, Carra A, Elovaara I, Fazekas F, Hartung HP, Hillert J, King J, Komoly S, Lubetzki C, Montalban X, Myhr KM, Ravnborg M, Rieckmann P, Wynn D, Young C, Filippi M, PreCISe study group. Effect of glatiramer acetate on conversion to clinically definite multiple sclerosis in patients with clinically isolated syndrome (PreClSe study): a randomised, double-blind, placebo-controlled trial. Lancet. 2009; 374:1503-11.

90. Arnold DL, Narayanan S, Antel S. Neuroprotection with glatiramer acetate: evidence from the PreCISe trial. J Neurol. 2013;260:1901-6.

91. Comi G, Martinelli V, Rodegher M, Moiola L, Leocani L, Bajenaru O, Carra A Elovaara I, Fazekas F, Hartung HP, Hillert J, King J, Komoly S, Lubetzki C, Montalban X, Myhr KM, Preziosa P, Ravnborg M, Rieckmann P, Rocca MA, Wynn D, Young C, Filippi M. Effects of early treatment with glatiramer acetate in patients with clinically isolated syndrome. Mult Scler. 2013;19: 1074-83.

92. Rovaris M, Comi G, Rocca MA, Wolinsky JS, Filippi M, European/Canadian Glatiramer Acetate Study Group. Short-term brain volume change in relapsing-remitting multiple sclerosis: effect of glatiramer acetate and implications. Brain. 2001;124(Pt 9):1803-12.
93. Sormani MP, Rovaris M, Valsasina P, Wolinsky JS, Comi G, Filippi M. Measurement error of two different techniques for brain atrophy assessment in multiple sclerosis. Neurology. 2004;62(8):1432-4.

94. Khan O, Rieckmann P, Boyko A, Selmaj K, Ashtamker N, Davis MD, Kolodny S, Zivadinov R. Efficacy and safety of a three-times-weekly dosing regimen of glatiramer acetate in relapsing-remitting multiple sclerosis patients: 3year results of the Glatiramer Acetate Low-Frequency Administration openlabel extension study. Mult Scler. 2016;23:818-29.

95. Fisher E, Nakamura K, Lee JC, You X, Sperling B, Rudick RA. Effect of intramuscular interferon beta-1a on gray matter atrophy in relapsing-remitting multiple sclerosis: a retrospective analysis. Mult Scler. 2016;22:668-76.

96. Cohen JA, Coles AJ, Arnold DL, Confavreux C, Fox EJ, Hartung HP, Havrdova E, Selmaj KW, Weiner HL, Fisher E, Brinar W, Giovannoni G, Stojanovic M, Ertik BI, Lake SL, Margolin DH, Panzara MA, Compston DA, CARE-MS I investigators. Alemtuzumab versus interferon $\beta$ 1a as first-line treatment for patients with relapsing-remitting multiple sclerosis: a randomised controlled phase 3 trial. CARE-MS I. Lancet. 2012;380:1819-28.

97. Coles AJ, Twyman CL, Arnold DL, Cohen JA, Confavreux C, Fox EJ, Hartung HP, Havrdova E, Selmaj KW, Weiner HL, Miller T, Fisher E, Sandbrink R, Lake SL, Margolin DH, Oyuela P, Panzara MA, Compston DA, CARE-MS ॥ investigators. Alemtuzumab for patients with relapsing multiple sclerosis after disease-modifying therapy: a randomised controlled phase 3 trial. CARE-MS II. Lancet. 2012;380:1829-39.

98. Rinaldi F, Perini P, Atzori M, Favaretto A, Seppi D, Gallo P. Disease-modifying drugs reduce cortical lesion accumulation and atrophy progression in relapsing-remitting multiple sclerosis: results from a 48-month extension study. Mult Scler Int. 2015;2015:369348.

99. Dwyer MG, Zivadinov R, Tao Y, Zhang X, Kennedy C, Bergsland N, Ramasamy DP, Durfee J, Hojnacki D, Weinstock-Guttman B, Hayward B, Dangond F, Markovic-Plese S. Immunological and short-term brain volume changes in relapsing forms of multiple sclerosis treated with interferon beta-1a subcutaneously three times weekly: an open-label two-arm trial. BMC Neurol. 2015;15:232

100. Seppi D, Polo D, Rinaldi F, et al. Effect of natalizumab on global and regional cortical thickness in RRMS: a four year longitudinal study highlights efficacy and stresses the importance of a well-timed intervention. Mult Scler J. 2016;22(S3):605

101. O'Connor P, Wolinsky JS, Confavreux C, Comi G, Kappos L, Olsson TP, Benzerdjeb H, Truffinet P, Wang L, Miller A, Freedman MS, TEMSO Trial Group. Randomized trial of oral teriflunomide for relapsing MS multiple sclerosis. N Engl J Med. 2011;365:1293-303.

102. Radue E, Sprenger T, Gaetano L et al. Teriflunomide slows down brain volume loss in relapsing MS: a SIENA analysis of the TEMSO MRI dataset. Presented at: 31 st Congress of the European Committee for Treatment and Research in Multiple Sclerosis. Barcelona, Spain, 7-10 October 2015.

103. Miller DH, Fox RJ, Phillips JT, Hutchinson M, Havrdova E, Kita M, WheelerKingshott CA, Tozer DJ, MacManus DG, Yousry TA, Goodsell M, Yang M, Zhang R, Viglietta V, Dawson KT, CONFIRM study investigators. Effects of delayed-release dimethyl fumarate on MRI measures in the phase 3 CONFIRM study. Neurology. 2015;84:1145-52.

104. Arnold DL, Gold R, Kappos L, Bar-Or A, Giovannoni G, Selmaj K, Yang M, Zhang R, Stephan M, Sheikh SI, Dawson KT. Effects of delayed-release dimethyl fumarate on MRI measures in the phase 3 DEFINE study. J Neurol. 2014;261:1794-802.

105. Dupuy SL, Tauhid S, Hurwitz S, Chu R, Yousuf F, Bakshi R. The effect of dimethyl fumarate on cerebral gray matter atrophy in multiple sclerosis. Neurol Ther. 2016:5:215-29.

106. Kappos L, Radue EW, O'Connor P, Polman C, Hohlfeld R, Calabresi P, Selmaj K, Agoropoulou C, Leyk M, Zhang-Auberson L, Burtin P. A placebocontrolled trial of oral fingolimod in relapsing multiple sclerosis. FREEDOMS study group. N Engl J Med. 2010;362:387-401.

107. Calabresi PA, Radue EW, Goodin D, Jeffery D, Rammohan KW, Reder AT, Vollmer T, Agius MA, Kappos L, Stites T, Li B, Cappiello L, von Rosenstiel P, Lublin FD. Safety and efficacy of fingolimod in patients with relapsingremitting multiple sclerosis (FREEDOMS II): a double-blind, randomised, placebo-controlled, phase 3 trial. Lancet Neurol. 2014;13:545-56.

108. De Stefano N, Tomic D, Radue EW, Sprenger T, Meier DP, Häring D, Sormani MP. Effect of fingolimod on diffuse brain tissue damage in relapsingremitting multiple sclerosis patients. Mult Scler Relat Disord. 2016;7:98-101.

109. Radue EW, Barkhof F, Kappos L, Sprenger T, Häring DA, de Vera A, von Rosenstiel P, Bright JR, Francis G, Cohen JA. Correlation between brain 
volume loss and clinical and MRI outcomes in multiple sclerosis. Neurology. 2015;84:784-93.

110. Sastre-Garriga J, Tur C, Pareto D, Vidal-Jordana A, Auger C, Río J, Huerga E, Tintoré M, Rovira A, Montalban X. Brain atrophy in natalizumab-treated patients: a 3-year follow-up. Mult Scler. 2015;21:749-56.

111. Magraner M, Coret F, Casanova B. The relationship between inflammatory activity and brain atrophy in natalizumab treated patients. Eur J Radiol. 2012;81:3485-90.

112. Mellergård J, Tisell A, Blystad I, Grönqvist A, Blennow K, Olsson B, Dahle C, Vrethem $M$, Lundberg P, Ernerudh J. Cerebrospinal fluid levels of neurofilament and tau correlate with brain atrophy in natalizumab-treated multiple sclerosis. Eur J Neurol. 2017;24:112-21.

113. Traboulsee A, Pelletier D, Comi G, et al. Alemtuzumab reduces the rate of brain volume loss in RRMS patients who switched from SC IFNB-1a to alemtuzumab (4-year-follow-up of the CARE-MS I and II studies). Mult Scler J. 2016;22(S3):613.

114. Borges IT, Shea CD, Ohayon J, Jones BC, Stone RD, Ostuni J, Shiee N, McFarland H, Bielekova B, Reich DS. The effect of daclizumab on brain atrophy in relapsing-remitting multiple sclerosis. Mult Scler Relat Disord. 2013;2:133-40

115. Montalban X, Hauser SL, Kappos L, Arnold DL, Bar-Or A, Comi G, de Seze J, Giovannoni G, Hartung HP, Hemmer B, Lublin F, Rammohan KW, Selmaj K, Traboulsee A, Sauter A, Masterman D, Fontoura P, Belachew S, Garren H, Mairon N, Chin P, Wolinsky JS, ORATORIO Clinical Investigators. Ocrelizumab versus placebo in primary progressive multiple sclerosis. N Engl J Med. 2017; 376:209-20.

116. Hauser SL, Bar-Or A, Comi G, Giovannoni G, Hartung HP, Hemmer B, Lublin F, Montalban X, Rammohan KW, Selmaj K, Traboulsee A, Wolinsky JS, Arnold DL, Klingelschmitt G, Masterman D, Fontoura P, Belachew S, Chin P, Mairon N, Garren H, Kappos L, OPERA I, Clinical Investigators OPERAll. Ocrelizumab versus interferon Beta-1a in relapsing multiple sclerosis. New Engl J Med. 2017;376:221-34.

117. Giovannoni G, Comi G, Cook S, Rammohan K, Rieckmann P, Soelberg Sørensen P, Vermersch P, Chang P, Hamlett A, Musch B, Greenberg SJ, CLARITY Study Group. A placebo controlled trial of oral cladribine for relapsing multiple sclerosis. N Engl J Med. 2010;362:416-26.

118. De Stefano N, Giorgio A, Battaglini M, De Leucio A, Hicking C, Dangond F, Giovannoni G, Sormani MP. Reduced brain atrophy rates are associated with lower risk of disability progression in patients with relapsing remitting multiple sclerosis treated with cladribine tablets. Mult Scler. 2017;2017:1-5.

\section{Submit your next manuscript to BioMed Central and we will help you at every step:}

- We accept pre-submission inquiries

- Our selector tool helps you to find the most relevant journal

- We provide round the clock customer support

- Convenient online submission

- Thorough peer review

- Inclusion in PubMed and all major indexing services

- Maximum visibility for your research

Submit your manuscript at www.biomedcentral.com/submit

C Biomed Central 